\title{
19 University
}

Touyz, R. M. (2017) Clinical Science-linking basic science to disease mechanisms. Clinical Science, 131(7), pp. 511-513.

There may be differences between this version and the published version. You are advised to consult the publisher's version if you wish to cite from it.

http://eprints.gla.ac.uk/138939/

Deposited on: 5 April 2017

Enlighten - Research publications by members of the University of Glasgow http://eprints.gla.ac.uk 


\title{
Clinical Science - linking basic science to disease mechanisms
}

\author{
Rhian Touyz, MBBCh, MSc(Med), PhD \\ Institute of Cardiovascular \& Medical Sciences \\ University of Glasgow, 126 University Place \\ Glasgow, N/A G12 8TA \\ United Kingdom \\ Editor-in-Chief, Clinical Science
}

Translating molecular bioscience and experimental research into medical insights, Clinical Science (published by Portland Press, the wholly-owned subsidiary of the Biochemical Society) has been offering multi-disciplinary coverage and clinical perspectives for nearly 50 years.

\section{What we publish}

The Journal publishes original papers and review articles of high scientific merit, covering the broad spectrum of biomedical specialities. The Journal publishes key findings in the fields of cardiovascular system, cerebrovascular system, gastrointestinal tract and liver, genetics and functional genomics, infection and immunity, inflammation and oncology, metabolism, endocrinology and nutrition, nephrology and circulation, respiratory system, and vascular biology. Testament to the quality, the Journal is ranked 16 out of 124 (within the top quartile) of journals in the Medicine (Research and Experimental) category of the 2015 Journal Citation Reports (Thomson Reuters).

Owing to the name "Clinical Science", we are sometimes mistaken for a medical journal that publishes Phase II/III clinical trials. However, the content published in Clinical Science is decidedly in the area of molecular mechanisms and pathways that explain, illustrate, and indeed underpin health/disease. In publishing such work, the aim of the Journal is to surface therapeutic targets of possible potential, to provide meaningful insight into future medical strategies and to inspire pharmacological innovation.

\section{Global experts to shepherd unique and insightful content}

We are very proud of the expertise that we have on the Editorial Board, and in 2016 we recruited new Associate Editors, complementing our existing Editorial Board. Professor Hongliang Li, based at the Medical Research Institute in Wuhan (China) specialises in the innate immunity network in cardiometabolic disorders, and also the cerebrovascular system. Professor Ilja Striz is Head of the Department of Clinical and Transplant Immunology at the Institute for Clinical and Experimental Medicine (IK+EM) in Prague (Czech Republic) and has expertise in immunity and inflammation. Finally, Associate Professor Ross Vlahos, based at the School of Health and Biomedical Sciences at RMIT University, Melbourne (Australia) is interested in the respiratory system, in particular asthma, chronic obstructive pulmonary disease, and lung inflammation.

2016 saw the publication of a series of papers on gender and molecular medicine, including commissioned review articles and key research. The themed collection, guest edited by Professor Jane Reckelhoff (University of Mississippi Medical Center, and current President of the American Physiological Society), includes papers by key researchers in the field, including members of the Board of the International Society for Gender Medicine, Giovannella Baggio, Marianne J. Legato, Virginia M. Miller and Vera Regitz-Zagrosek. We are looking forward in 2017 to producing a similar themed collection on small vessels, dementia and chronic diseases. This was initiated by the 
Vascular Experimental Theme of the Dementias Platform UK, and complements a workshop that was held in January 2017 bringing together key players in dementia and stroke research. The themed collection will be guest edited by Professor Joanna Wardlaw (Chair of Applied Neuroimaging and Head of Neuroimaging Sciences, University of Edinburgh). An editorial introducing the collection is already available at http://www.clinsci.org/content/130/21/1875.

Commissioned review articles in the journal highlight key areas of research, and Professor Mark Cooper (Head of the Department of Diabetes, Central Clinical School, Monash University, Australia) overseas the process as Reviews Editor. Our review articles are often specifically invited papers from experts around the world and the articles and topics are selected to be unique and insightful advances on existing knowledge. Review papers from 2016 that show the breadth of Clinical Science coverage include:

- Molecular mechanisms for vascular complications of targeted cancer therapies (Srila Gopal, Kenneth B. Miller, Iris Z. Jaffe)

- Energy balance, body composition, sedentariness and appetite regulation: pathways to obesity (Mark Hopkins, John E. Blundell)

- Protein kinase $\mathrm{C}$ mechanisms that contribute to cardiac remodelling (Alexandra C. Newton, Corina E. Antal, Susan F. Steinberg)

- Mitochondrial health, the epigenome and healthspan (Miguel A. Aon, Sonia Cortassa, Magdalena Juhaszova, Steven J. Sollott)

- Neurotrophin signalling: novel insights into mechanisms and pathophysiology (Mariela Mitre, Abigail Mariga, Moses V. Chao)

\section{Image Library}

I am particularly proud of the Clinical Science Image Library. The library is a collection of figures from selected papers published in the journal, all of which are curated by keyword. The figure is provided along with the figure caption and a link to the abstract of the original paper. Each month, one of the Clinical Science Associate Editors chooses an image of the month that is promoted by the Journal and Portland Press and this receives a good amount of interest via Twitter. Whether seeking a diagram for explaining the mechanism of action for everolimus [1] or seeking a pathway depiction of the NADPH-oxidase regulated inflammatory response [2], a rich variety of images are available via the journal's Image Library.

\section{Your translational research}

Why not join your colleagues and peers in submitting your work to the Journal for consideration? We welcome all research with a translational aspect to the work, and we encourage you to submit research that links basic science to disease mechanisms to clinsci.msubmit.net. Equally, if you have a pre-submission query, please send this to editorial@portlandpress.com.

Papers published in Clinical Science emphasise the translational nature of science and any articles submitted need to ensure that the basic science research being reported translates into benefits for human health and disease. To speak to this, all papers published in the Journal carry a 'Clinical Perspectives' section. This section helps to focus the authors and the readers to the translational aspect of the work, covering the following three bullet points: (i) background as to why the study was undertaken, (ii) a brief summary of the results, and (iii) the potential significance of the results to human health and disease. 
All submitted articles that are deemed suitable for formal consideration by the Editorial Board will receive full and fair peer review. In most cases, a first decision is returned to submitting authors within 30 days. We look forward to working with you on the consideration and possible publication of your next article in Clinical Science.

\section{References}

1 Saran, U., Foti, M. and Dufour, J.-F. (2015) Cellular and molecular effects of the mTOR inhibitor everolimus. Clin. Sci. 129, 895-914

2 Single, K.L. and Segal, B.H. (2016) NOX2-dependent regulation of inflammation. Clin. Sci. $130,479-490$ 